\title{
Everting suture correction of lower lid involutional entropion
}

\author{
Mark Wright, Dugald Bell, Chris Scott, Brian Leatherbarrow
}

\begin{abstract}
Aims-To assess the long term efficacy of everting sutures in the correction of lower lid involutional entropion and to quantify the effect upon lower lid retractor function.

Methods-A prospective single armed clinical trial of 62 eyelids in 57 patients undergoing everting suture correction of involutional entropion. Patients were assessed preoperatively and at $6,12,24$, and 48 months postoperatively. The main outcome variables were lower lid position and the change in lower lid retractor function. Results-When compared with the nonentropic side, the entropic lid had a greater degree of horizontal laxity and poorer lower lid retractor function. These differences however, were not significant. At the conclusion of the study and after a mean follow up period of 31 months, the entropion had recurred in $15 \%$ of the patients. There were no treatment failures in the group of five patients with recurrent entropion. The improvement in lower lid retractor function after the insertion of lower lid everting sutures did not reach statistical significance. There was no significant difference between the treatment failure group and the group with a successful outcome with regard to: the degree of horizontal lid laxity or lower lid retractor function present preoperatively; patient age or sex; an earlier history of surgery for entropion. There was neither a demonstrable learning effect nor a significant intersurgeon difference in outcome. The overall 4 year mortality rate was $30 \%$. Conclusions-The use of everting sutures in the correction of primary or recurrent lower lid involutional entropion is a simple, successful, long lasting, and cost effective procedure.

(Br F Ophthalmol 1999;83:1060-1063)
\end{abstract}

Princess Alexandra Eye Pavilion, Edinburgh

M Wright

$\mathrm{R}$ W D Bell

C M Scott

Manchester Royal Eye Hospital

B Leatherbarrow

Correspondence to: Dr M Wright, Princess Alexandra Eye Pavilion, Edinburgh EH3 9HA.

Accepted for publication 4 May 1999
Every structure of the eyelid has been the object of surgery. Various medical treatments including skin patches, ${ }^{15}$ botulinum toxin, ${ }^{16}$ and tissue glue ${ }^{17}$ have been advocated. Everting sutures have been used for the correction of lower lid entropion since the time of Hippocrates $^{18}$ and remain the most simple form of surgical treatment. ${ }^{19-24}$ Without exception, everting sutures have been considered to offer only a temporary cure for patients with entropion. ${ }^{13591725-27}$

Despite a plethora of publications describing various surgical techniques, none has attempted to quantify the effects of surgery upon the eyelid variables thought to be important in the aetiology of involutional entropion. We attempted to measure the lower lid retractor function and the degree of horizontal lid laxity present, firstly, in order to quantify the effects of our intervention and, secondly, to attempt to identify those patients in whom everting sutures are more likely to fail.

\section{Patients and methods}

After informed consent was obtained, 62 eyelids from 57 subjects were entered into a prospective single armed clinical trial of patients undergoing everting suture correction of lower lid involutional entropion (Fig 1). Follow up was complete in 38 of 57 patients (17 patients died during the study, one patient was enucleated, and one patient was lost to follow up between the 24 and 48 month visits). The mean duration of follow up was 31 months (range 1-49).

After the conjunctiva was anaesthetised using topical $0.4 \%$ benoxinate, approximately $1 \mathrm{ml}$ of $2 \%$ lignocaine containing 1 in 200000 units of adrenaline was injected subcutaneously into the lower lid. The surgical technique is essentially the same as that described by Feldstein. ${ }^{24}$ The distance between the punctum and the lateral canthus is divided into quarters with the junction between the most medial and adjacent quarters being the entry point for the first suture. The other two pairs of sutures are inserted at the junction of the remaining quarters. The double armed $4 / 0$ plain catgut sutures (W 813, Ethicon, UK) are prepacked in alcohol which was not rinsed off before use. The sutures are passed in a horizontal mattress fashion, the first needle engages the lower lid retractors which are seen as a subconjunctival, infratarsal white band at the lowest point of the inferior conjunctival fornix. The skin of the lower lid is pulled downwards everting the anterior lamella and the needle is advanced upwards to pierce the skin $3 \mathrm{~mm}$ below the lid margin. The other arm of the suture is passed 


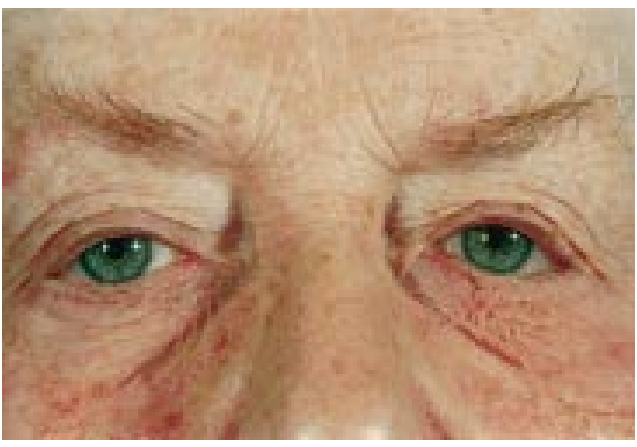

Figure 1 Preoperative appearance.

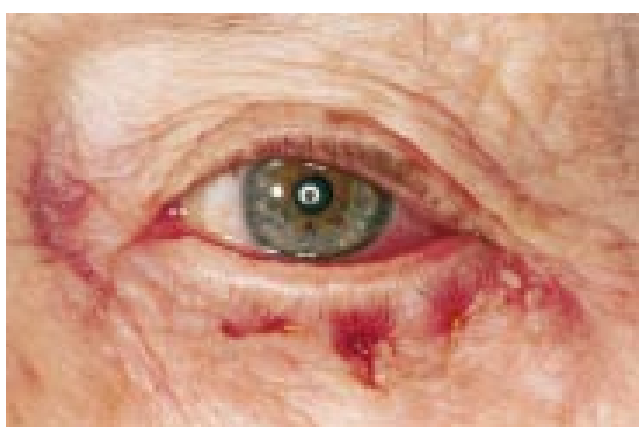

Figure 2 Immediate postoperative appearance.

$2 \mathrm{~mm}$ lateral to the first arm in an identical fashion. The sutures are tied tightly to produce $1 \mathrm{~mm}$ of postoperative ectropion (Fig 2). No topical antibiotics are used and the sutures are allowed to fall out spontaneously.

Patients were assessed preoperatively and at 6, 12, 24, and 48 months postoperatively. Preoperative and postoperative data collection included an estimation of the lower lid retractor function and the horizontal lid laxity (HLL) for both eyelids. The lower lid retractor function was indirectly estimated by measuring the vertical excursion in millimetres of the centre of the lower lid margin between extreme upgaze and downgaze. This measurement was termed the lower lid excursion (LLE). The HLL was estimated by measuring with Castroviejo calipers the distance in millimetres the centre of the posterior margin of the lower lid could be distracted forwards from the limbus. All intraoperative and postoperative complications were noted. The 48 month postoperative visit was conducted by CMS who was masked to the treatment side. We included in our definition of success those patients who died during the study period who were noted to have a normal lid position at the preceding visit. Similarly, in calculating the cumulative failure rates we included these patients in order simplify the reporting of the results.

The differences between the entropic and non-entropic lids in terms of the LLE and HLL and also the postoperative change in the LLE and HLL were analysed using the paired Student's $t$ test. The group of patients with a successful outcome were compared with those in the treatment failure group using the $\chi^{2}$ test. For all statistical tests $\mathrm{p}$ values of $<0.05$ were considered to be statistically significant.

\section{Results}

The mean age of the study group was 78 years (range 53-95), 32/57 (56\%) of the patients were female, $5 / 57(9 \%)$ had bilateral entropion, and 5/57 (9\%) had recurrent entropion. The five patients with recurrent entropion had undergone a variety of surgical corrections, all of which had included a horizontal lid shortening procedure. All surgery was performed by MW or RWDB.

\section{INTERLID COMPARISON IN UNILATERAL}

ENTROPION

The mean preoperative LLE of the entropic lid was $4.2 \mathrm{~mm}$ (SD 0.9, range 2-7), the mean preoperative LLE of the contralateral nonentropic lid was $4.6 \mathrm{~mm}(1.1,2-7)$. There was no significant difference in the LLE when the entropic and non-entropic sides were compared $\mathrm{p}=0.097(\mathrm{n}=52)$.

The mean preoperative HLL of the entropic lid was $7.8 \mathrm{~mm}(2.2,4-13)$, the mean preoperative HLL of the contralateral nonentropic lid was $7.6 \mathrm{~mm}(1.7,5-12)$. There was no significant difference in the HLL when the entropic and non-entropic sides were compared $\mathrm{p}=0.649(\mathrm{n}=52)$.

POSTOPERATIVE CHANGE IN THE LLE AND HLL The mean preoperative LLE of the entropic lid was $4.2 \mathrm{~mm}(1.0,2-7)$, the mean (mean of $6,12,24$, and 48 month postoperative measurements) postoperative LLE was $4.3 \mathrm{~mm}$ (1.0, 2.7-7.0). There was no significant change in the LLE when the preoperative and postoperative values were compared $p=0.405(n=59$; three deaths before the 6 month visit).

The mean preoperative HLL of the entropic lid was $7.8 \mathrm{~mm}(2.2,4-13)$, the mean (mean of $6,12,24$, and 48 month postoperative measurements) postoperative HLL was $7.9 \mathrm{~mm}$ (1.6, 4.5-11.0). There was no significant change in the HLL when the preoperative and postoperative values were compared $\mathrm{p}=0.602$ $(n=59)$.

POSTOPERATIVE LID POSITION

At the conclusion of the study and after a mean follow up period of 31 months, the entropion had recurred in $9 / 61 \quad(15 \%)$ eyelids. The cumulative failure rates were $4 / 62(7 \%)$ at 6 months, $6 / 62(10 \%)$ at 12 months, $7 / 62(12 \%)$ at 24 months, and $9 / 61(15 \%)$ at 48 months. There were no treatment failures in the group of five patients with recurrent entropion.

\section{MORTALITY DATA}

Cumulative mortality rates were $3 / 57(5 \%)$ at 6 months, $8 / 57$ (14\%) at 12 months, $13 / 57$ $(23 \%)$ at 24 months, and $17 / 57(30 \%)$ at 48 months.

For the comparison of the treatment success and failure groups see Table 1.

COMPLICATIONS

One patient developed an acute inflammatory reaction around each of the sutures which settled after a course of flucloxacillin. Two patients were noted to have a minimal degree of ectropion at the 6 month visit which was 
Table 1 Comparison of the treatment success and failure groups

\begin{tabular}{|c|c|c|c|}
\hline & Success $($ no (\%)) & Failure (no) & $p$ Value ${ }^{\star}$ \\
\hline \multicolumn{4}{|c|}{ Horizontal lid laxity (HLL) } \\
\hline minimal $(4-8 \mathrm{~mm})$ & $27(82)$ & 6 & 0.382 \\
\hline maximal $(9-13 \mathrm{~mm})$ & $26(90)$ & 3 & \\
\hline \multicolumn{4}{|c|}{ Lower lid excursion (LLE) } \\
\hline minimal $(2-4 \mathrm{~mm})$ & $35(90)$ & 4 & 0.215 \\
\hline maximal $(5-7 \mathrm{~mm})$ & $18(78)$ & 5 & \\
\hline \multicolumn{4}{|l|}{ Patient age (years) } \\
\hline $53-79$ & $24(83)$ & 5 & 0.957 \\
\hline $80-95$ & $24(86)$ & 4 & \\
\hline \multicolumn{4}{|l|}{ Patient sex } \\
\hline male & $19(76)$ & 6 & 0.133 \\
\hline female & $29(91)$ & 3 & \\
\hline \multicolumn{4}{|l|}{ Previous surgery } \\
\hline recurrent entropion & $5(100)$ & 0 & 0.337 \\
\hline primary entropion & $48(84)$ & 9 & \\
\hline \multicolumn{4}{|l|}{ Timing of surgery } \\
\hline 1 st half of study & $27(87)$ & 4 & 0.688 \\
\hline 2nd half of study & $28(90)$ & 3 & \\
\hline \multicolumn{4}{|l|}{ Surgeon } \\
\hline A & $32(89)$ & 4 & 0.370 \\
\hline $\mathrm{B}$ & $21(81)$ & 5 & \\
\hline
\end{tabular}

asymptomatic and which settled spontaneously. One patient was enucleated (for endophthalmitis which was unrelated to the everting sutures). Thirty per cent of the patients died during the study period from causes unrelated to the surgery.

\section{Discussion}

INTERLID COMPARISON IN UNILATERAL ENTROPION

This study did not demonstrate a significant difference in the function of the lower lid retractors or in the degree of horizontal laxity when the entropic and non-entropic lids were compared. Jones et $a l^{8}$ described a loss of lower lid retraction movement accompanying downgaze in involutional entropion and attributed this to an attenuation of the lower lid retractors. Both this study and that of Benger and Musch $^{1}$ failed to demonstrate any such loss of retraction movement. The retention of normal vertical excursions by lower eyelids with involutional entropion parallels the retention of normal excursions by upper eyelids with involutional (aponeurogenic) ptosis. Benger and Musch $^{1}$ demonstrated a significant increase in horizontal laxity in patients in whom the entropion was present for more than 6 weeks.

\section{MECHANISM OF ACTION}

Everting sutures plicate the attenuated lid retractors and transfer their pull to the anterior surface of the tarsal plate. They also create a horizontal barrier to the upward migration of the preseptal orbicularis. The permanence of the procedure depends on the creation of a fibrotic scar along the suture tracks. Seiff et $a l^{25}$ demonstrated an aggressive fibrotic and inflammatory response in the tissues of the lower lid 2 weeks after the insertion of everting sutures. We chose to leave the sutures unrinsed in order to heighten the inflammatory response and enhance the developing cicatrix.

POSTOPERATIVE CHANGE IN THE LOWER LID RETRACTOR FUNCTION

Collin and Rathbun ${ }^{9}$ described a subjective increase in lower lid excursion after a Quick-

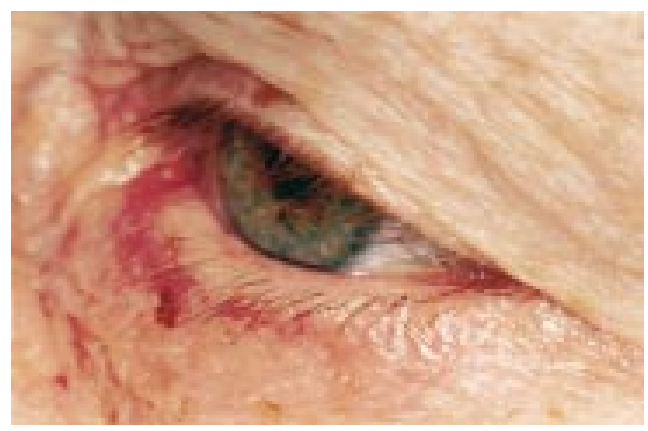

Figure 3 Three month postoperative appearance of the same patient as depicted in Figures 1 and 2.

ert's entropion repair and interpreted this as evidence of an improvement in lower lid retractor function. As our quantitative method of assessing retractor function failed to distinguish the entropic from the non-entropic side it is perhaps not surprising that we failed to demonstrate any significant change in lower lid retractor function after the insertion of everting sutures.

POSTOPERATIVE LID POSITION

At the conclusion of the study, the entropion had recurred in only nine of $61(15 \%)$ lids with no treatment failures in the group of five patients with recurrent entropion. Recurrence of entropion following retractor tightening is almost exclusively associated with coexisting, uncorrected horizontal lid laxity. ${ }^{5} 101728$ There was, however, no significant difference in the degree of horizontal lid laxity (or lower lid retractor function) present preoperatively when the treatment success and treatment failure groups were compared. Indeed, the treatment failure group demonstrated a smaller degree of horizontal lid laxity than the treatment success group $(7.2 \mathrm{~mm} v 8.1 \mathrm{~mm})$. Neither the age nor the sex of the patients influenced the outcome.

\section{CONCLUSION}

Everting sutures can be inserted quickly, simply, safely, cheaply (the cost of each suture pack is $£ 2.13$ ) and often at the patient's first appointment. As the overall mortality rate of $30 \%$ demonstrates, the vast majority of patients with entropion are elderly, often with many of the medical and social problems experienced by this group. In contrast with incisional lid surgery, anticoagulation therapy need not be omitted nor surgery delayed in the hypertensive patient.

There were no significant perioperative or postoperative complications. In the nine patients in whom the entropion recurred, no significant lid scarring was encountered during the repeat surgery (Quickert). The overall cosmesis was excellent, CMS was unable to detect which side had undergone the procedure in over $95 \%$ of cases examined (Fig 3 ). Our overall recurrence rate of $15 \%$ after 48 months of follow up is significantly higher than the frequently published recurrence rate of $0 \%{ }^{42629}{ }^{30}$ following incisional surgery. These impressive results in part reflect the various authors' oculoplastic interest and expertise. In 
contrast, everting sutures can be quickly and correctly inserted by a practitioner with minimal surgical experience. There was no evidence of the presence of a learning curve nor a significant intersurgeon difference in outcome.

It is generally accepted that the long term likelihood of success of any entropion surgery (including everting sutures) is dependent upon the correction of the underlying impairment in lower lid retractor function. Benger and Musch ${ }^{1}$ demonstrated a significant increase in the "vertical distraction distance" in entropic eyelids which was thought to reflect an attenuation or disinsertion of the lower lid retractors. Perhaps if we had chosen this method of measurement rather than the LLE we may have detected a quantifiable improvement in retractor function after the insertion of everting sutures.

Based upon the results of this clinical trial, everting sutures can be recommended in the management of lower lid involutional entropion, particularly for the group of patients mentioned above.

1 Benger RS, Musch DC. A comparative study of eyelid parameters in involutional entropion. Ophthalmic Plast Reconstr Surg 1989;5:281-7.

2 Bick MW. Surgical management of orbital tarsal disparity. Arch Ophthalmol 1965;75:386-9.

3 Rainin EA. Senile entropion. Arch Ophthalmol 1979;97:928 30.

4 Jackson ST. Surgery for involutional entropion. Ophthalmic Surg 1983;14:322-6.

5 Wesley RE, Collins JW. Combined procedure for senile entropion. Ophthalmic Surg 1983;14:401-5.

6 Schaefer AJ. Variation in the pathophysiology of involutional entropion and its treatment. Ophthalmic Surg 1983;14:6535.

7 Jones LT. The anatomy of the lower eyelid, and its relation to the cause and cure of entropion. Am f Ophthalmol 1960 49:29-36.

8 Jones LT, Reeh MJ, Wobig JL. Senile entropion: a new concept for correction. Am f Ophthalmol 1972;74:327-9.
9 Collin JRO, Rathbun JE. Involutional entropion-a review with evaluation of a procedure. Arch Ophthalmol 1978;96: with evaluat

10 Dryden RM, Leibsohn J, Wobig J. Senile entropionpathogenesis and treatment. Arch Ophthalmol 1978;96: 1883-5.

11 Hargiss JL. Inferior aponeurosis revisited. Ophthalmology 1980;87:1001-4.

12 Hawes MJ, Dortzbach RK. The microscopic anatomy of the lower lid retractors. Arch Ophthalmol 1982;100:1313-8.

13 Dortzbach RK, McGetrick JJ. Involutional entropion of the lower eyelid. Adv Ophthalmic Plast Reconstr Surg 1983;2: 257-67.

14 De Roeth A. Mechanism of the senile entropion. Trans Pac Coast Oto-Ophthalmol Soc 1963;44:173-7.

15 Irvine S, Francis IC, Bishop AE, et al. The entropion patch: a method of temporarily correcting involutional entropion with adhesive tape. Ophthalmic Surg 1994;25:604-6.

16 Clarke JR, Spalton DJ. Treatment of senile entropion with botulinum toxin. Br F Ophthalmol 1988;72:361-2.

17 Hedin A. Senile entropion-cure rate by retractor tightening and horizontal shortening. Acta Ophthalmol 1997;75: $443-6$

18 Beard CH. In: Ophthalmic surgery. 2nd ed. Philadelphia: Blakiston Co, 1914:255-7

19 Gaillard AL. Suture pour L'entropion. Ann Oculist (Paris) 1847;18:241.

20 Arlt CF. Die Krankheiten des Auges Fur praktische Aertze geschildert. Prague: Credner, 1854;3:368.

21 Snellen H. Suture for entropion. Congress Internationale d'ophthalmologie (Paris) 1863:236.

22 Stellwag von C. Ein neues Verfahren gegen einwartsgekehrte Wimptern. Allg Wein Med Zeitung 1893;28:527.

23 Quickert MH, Rathbun JE. Suture repair of entropion. Arch Ophthalmol 1971;85:304-5.

24 Feldstein $M$. Suture correction of senile entropion by inferior lid retractor tuck. Adv Ophthalmic Plast Reconstr Surg 1983;2:269-74

25 Seiff SR, Kim M, Howes EL. Histopathological evaluation of rotation sutures for involutional entropion. Brf Ophthalmol 1989;73:628-32.

26 Dresner RM, Karesh JW. Transconjunctival entropion repair. Arch Ophthalmol 1993;111:1144-8.

27 Collin JRO. Entropion. In: A manual of systematic eyelid surgery. 2nd ed. London: Churchill Livingstone, 1989

28 Lance SE, Wilkins RB. Involutional entropion. A retrospective analysis of the Weis procedure alone or combined with horizontal procedure. Ophthalmic Plast Reconstr Surg 1991; horizontal

29 Charonis GC, Gossman MD. Involutional entropion repair by posterior lamella tightening and myectomy. Ophthalmic Plast Reconstr Surg 1996;12:98-103.

30 Mauriello JA, Abdelsalam A. Modified corncrib (inverted T) procedure with Quickert suture for repair of involutional entropion. Ophthalmology 1997;104:504-7. 